\title{
BMJ Open Fetal Doppler velocimetry and bronchopulmonary dysplasia risk among growth-restricted preterm infants: an observational study
}

\author{
Alessandra Lio, ${ }^{1}$ Paolo Rosati, ${ }^{2}$ Roberta Pastorino, ${ }^{3}$ Francesco Cota, ${ }^{1}$ \\ Milena Tana, ${ }^{1}$ Chiara Tirone, ${ }^{1}$ Claudia Aurilia, ${ }^{1}$ Cinzia Ricci, ${ }^{1}$ \\ Alessandro Gambacorta, ${ }^{1}$ Angela Paladini, ${ }^{1}$ Ilenia Mappa, ${ }^{2}$ Silvia Buongiorno, ${ }^{2}$ \\ Gian Franco Zannoni, ${ }^{4}$ Costantino Romagnoli, ${ }^{1}$ Giovanni Vento ${ }^{1}$
}

To cite: Lio A, Rosati P, Pastorino R, et al. Fetal Doppler velocimetry and bronchopulmonary dysplasia risk among growthrestricted preterm infants: an observational study. BMJ Open 2017;7:e015232. doi:10.1136/ bmjopen-2016-015232

- Prepublication history for this paper is available online. To view these files please visit the journal online (http://dx.doi. org/10.1136/bmjopen-2016015232).

Received 25 November 2016 Revised 13 June 2017 Accepted 14 June 2017

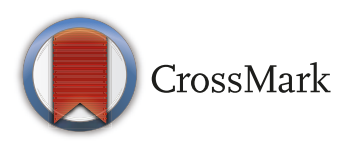

${ }^{1}$ Division of Neonatology, Fondazione Policlinico Universitario A. GemelliUniversità Cattolica del Sacro Cuore, Rome, Italy

${ }^{2}$ Department of Obstetrics and Gynecology, Fondazione Policlinico Universitario A. Gemelli-Università Cattolica del Sacro Cuore, Rome, Italy ${ }^{3}$ Section of Hygiene, Institute of Public Health, Università Cattolica del Sacro Cuore, Rome, Italy

${ }^{4}$ Department of Pathology,

Fondazione Policlinico

Universitario A. Gemelli-

Università Cattolica del Sacro

Cuore, Rome, Italy

Correspondence to

Dr Giovanni Vento; giovanni.

vento@unicatt.it

\section{ABSTRACT}

Objective To investigate whether fetal growth restriction (FGR) diagnosis, based on pathological prenatal fetal Doppler velocimetry, is associated with bronchopulmonary dysplasia (BPD) independently of being small for gestational age (SGA) per se at birth among very preterm infants.

Design Prospective, observational study. FGR was defined as failing fetal growth in utero and fetal Doppler velocimetry abnormalities.

Setting Policlinico Universitario Agostino Gemelli, Roma, Italy.

Patients Preterm newborns with gestational age $\leq 30$ weeks and birth weight $(\mathrm{BW}) \leq 1250 \mathrm{~g}$.

Main outcome measures Bronchopulmonary dysplasia. Results In the study period, 178 newborns were eligible for the study. Thirty-nine infants (22\%) were considered fetal growth-restricted infants. Among the 154 survived babies at 36 weeks postmenstrual age, 12 out of $36(33 \%)$ of the FGR group developed BPD versus 8 out of $118(7 \%)$ of the NO-FGR group $(p<0.001)$. BPD rate was sixfold higher among the SGA-FGR infants compared with the SGA-NO-FGR infants. In a multivariable model, FGR was significantly associated with BPD risk (OR 5.1, Cl 1.4 to 18.8, $p=0.01$ ), independently from $B W Z$-score that still remains a strong risk factor ( $\mathrm{OR} 0.5, \mathrm{Cl} 0.3$ to $0.9, \mathrm{p}=0.01$ ). Conclusion Among SGA preterm infants, BPD risk dramatically increases when placenta dysfunction is the surrounding cause of low BW. Antenatal fetal Doppler surveillance could be a useful tool for studying placenta wellness and predicting BPD risk among preterm babies. Further research is needed to better understand how FGR affects lung development.

\section{INTRODUCTION}

Bronchopulmonary dysplasia (BPD) is one of the most concerning complications of very preterm birth as it leads to frequent hospitalisations, persistent abnormal lung function and neurodevelopmental impairment. ${ }^{1}{ }^{2}$ Recently, fetal growth restriction (FGR) has been suggested as an additional risk factor
Strengths and limitations of this study

- This is one of the first studies defining fetal growth restriction as the coexistence of failing of fetal growth and abnormal fetal Doppler velocimetry rather than just a low birth weight (BW).

- We reported that small for gestational age preterm infants have the highest bronchopulmonary dysplasia (BPD) risk when placenta dysfunction is the surrounding cause of low BW.

- The small sample size of BPD infants could limit the power of our estimates.

- Different Doppler patterns were not considered in the analyses, as well as the exact duration of time the fetus was exposed to abnormal Doppler flows.

for BPD both in human and animal studies. ${ }^{3-6}$ The presence of uteroplacental insufficiency leads to physiological, metabolic and haemodynamic adaptations that can affect development of the FGR fetus. FGR is a common condition of preterm births but there is a lack of standard definitions in literature. In several published works, FGR infants were considered those small for gestational age (SGA), but a significant proportion of smallness is due to constitutional causes. FGR is probably the result of underlying placental pathology and occurs when the growth restriction is pathological, indicating that the fetus has failed to achieve its full growth potential. ${ }^{7}$ An adverse environment before birth could interfere with development and lead to fetal epigenetic changes that increase vulnerability of the lungs after birth. Up to now, several studies have suggested an association between placental disorders affecting fetal wellness and BPD. ${ }^{8-11}$ Aim of this study was to evaluate whether FGR diagnosis, based on pathological prenatal fetal Doppler velocimetry, is 
associated with BPD independently of being SGA per se in a cohort of preterm infants.

\section{MATERIALS AND METHODS}

The study included newborns with gestational age (GA) $\leq 30$ weeks and birth weight (BW) $\leq 1250$ g consecutively admitted to our neonatal intensive care unit (NICU) in the period from January 2009 to June 2013. Data about prenatal and neonatal characteristics were prospectively collected in the obstetric medical record and Neonatal Unit database, respectively.

FGR diagnosis was based on the coexistence of failing fetal growth in utero, defined as the reduction of the estimated fetal weight of at least $1 \mathrm{SD}$ in two ultrasound scans within 2 weeks and fetal Doppler velocimetry abnormalities, defined as the presence of one of the following conditions: ${ }^{11}$

- umbilical artery pulsatility index (PI) greater than the 95th centile,

- absent or reversed end diastolic flow velocities on at least $50 \%$ of the Doppler waveforms from the umbilical artery on at least one occasion during pregnancy,

- cerebral redistribution, defined as occurring when both the umbilical artery PI is greater than the 95th centile and the middle cerebral artery PI is less than the 5 th centile for GA.

The Doppler studies were performed by two certified perinatologists (PR and IM). The last Doppler assessment was done between 48 hours and 5 days before delivery.

The exclusion criteria were:

- no fetal Doppler velocimetry information available,

- major congenital malformation,

- hydrops fetalis,

- prolonged preterm rupture of membranes (pPROM) that occurred more than 3 weeks before the delivery,

- suspected twin-to-twin transfusion.

The BW was recorded and the BW z-score was calculated for each infant. According to the most common definition, SGA infants were those with a BW $<10$ th percentiles (z-score $<-1.28$ ) for GA on Bertino growth curves for Italian babies, independently from their fetal Doppler velocimetry. ${ }^{12}$ GA was estimated by the first trimester ultrasound. Maternal pre-eclampsia was diagnosed in previously normotensive woman with onset of hypertension and proteinuria after 20 weeks of gestation according to the American Congress of Obstetricians and Gynaecologists criteria. ${ }^{13}$ Histological chorioamnionitis was diagnosed when the chorion-amnion contained a polymorphonuclear leucocytic infiltrate accompanied by oedema and congestion of the vessels. ${ }^{14}$ Placental histology was performed by a single pathologist who was unaware of the patient's history and evolution. Two main causes of delivery were identified: $:^{15}$ an 'indicated' preterm delivery (for a placenta dysfunction disorder such as FGR, maternal pre-eclampsia, pregnancy-related hypertension) and a 'spontaneous' preterm delivery (triggered by an inflammatory condition such as pPROM, cervical insufficiency and preterm labour). Antenatal corticosteroids were considered to have been administered if at least two betamethasone doses were given 24 hours apart and the delivery took place not less than 24 hours and no more than 7 days after the last dose.

BPD, the primary outcome, was defined as oxygen dependency at 36 weeks of postmenstrual age (PMA). ${ }^{16}$ Secondary outcomes included the incidence of respiratory distress syndrome (RDS) and its severity (need of $\geq 2$ doses of surfactant), persistent pulmonary hypertension of the newborn (PPHN) requiring inhaled nitric oxide (iNO) therapy according to our local protocols, sepsis (defined as the presence of clinical signs of infection with a positive blood culture for bacteria or fungi), pneumonia (defined as clinical sign of infection and a positive bronchoalveolar lavage fluid culture for bacteria or fungi), severe intracranial haemorrhage (IVH) (grade 3 or 4 according to Papile's classification), haemodynamically significant patent ductus arteriosus (Hs-PDA) (ductal diameter $>1.6 \mathrm{~mm}$, growing or pulsatile ductus flow from left to right, reversal of flow in the descending aorta, increased left atrium to aortic ratio $>1.3$ ), duration of mechanical ventilation and duration of oxygen therapy.

Clinical strategies were unchanged throughout the study period. American Heart Association Guidelines for neonatal resuscitation were applied in the delivery room. ${ }^{17}$ All the babies received caffeine at the admission in NICU. If intubation was needed (at birth or after non-invasive ventilation support failure), elective high-frequency oscillatory ventilation was performed with Draeger Babylog 8000 plus (Draeger, Lubeck, Germany) ${ }^{18}$ providing gentle ventilation and early extubation. We used Curosurf (Chiesi Farmaceutici) at a dose of $200 \mathrm{mg} / \mathrm{kg}$ as RDS treatment and iNO therapy for PPHN. Continuous positive airway pressure was always applied after extubation. All the newborns received ibuprofen therapy in case of Hs-PDA. Surgery was performed if an Hs-PDA persisted after two courses of ibuprofen or if it was contraindicated. ${ }^{19}$

\section{Statistical analyses}

A descriptive analysis was conducted to report prenatal and neonatal characteristics of the studied neonates. Values were expressed as mean and SD for continuous variables or absolute frequency and percentages for categorical variables. Comparison of continuous variables between groups was evaluated by the $t$ test, and comparison of categorical variables was appraised by the $\mathrm{Z}$ test for the difference between two proportions or the Fisher test as appropriate. A p value $<0.05$ was considered significant. In order to evaluate the association between the BPD risk and each explanatory variable, a univariable analysis was performed using a logistic regression model by including one variable at a time. 'Prenatal and early-birth history'-related independent variables found to be significant in the univariable analyses ( $p$ value equal or lower than 0.05 ) were included in the multivariable model. A likelihood ratio test was used to compare the goodness of fit 


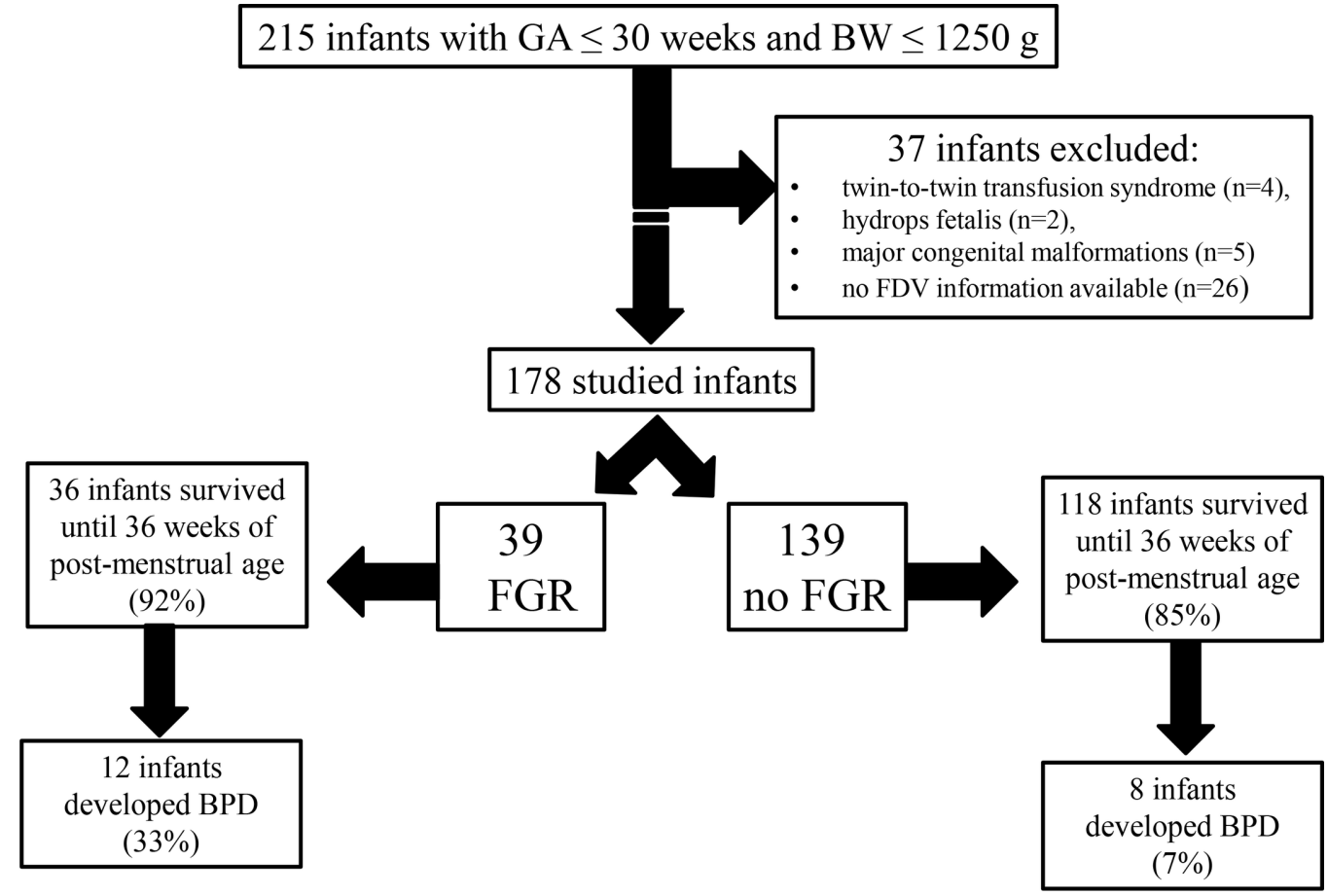

Figure 1 Flow diagram of the study participants. BPD, bronchopulmonary dysplasia; BW, birth weight; FDV, fetal Doppler velocimetry; FGR, fetal growth restriction; GA, gestational age.

of the models and for selection of the most appropriate model. ${ }^{20}$ Statistical analyses were done with Stata version 2013 software (Stata Statistical Software: Release 13, College Station, Texas, USA).

\section{Ethical approval}

The study protocol was approved by the Ethics Committee of the Policlinico Universitario A. Gemelli-Università Cattolica del S. Cuore.

\section{RESULTS}

In the study period, 215 newborns with GA $\leq 30$ weeks and $\mathrm{BW} \leq 1250 \mathrm{~g}$ were admitted to our NICU. Thirty-seven newborns were excluded because of twin-to-twin transfusion syndrome $(n=4)$, hydrops fetalis $(n=2)$, major congenital malformations $(n=5)$ and no fetal Doppler velocimetry information available $(\mathrm{n}=26)$. Consequently, 178 newborns were eligible for the study (figure 1). All the mothers of the studied infants underwent to a prenatal surveillance programme for pregnancy at risk of preterm birth that included a fetal Doppler examination.

Thirty-nine infants $(22 \%)$ were considered FGR infants as they had a failing fetal growth and an abnormal fetal Doppler velocimetry. As shown in table 1, FGR infants were significantly more mature than NO-FGR infants and their BW was significantly lower with consequent BW z-score significantly lower than in NO-FGR group. FGR infants received antenatal corticosteroids more frequently than the others did $(97 \%$ vs $83 \%)$. Histological chorioamnionitis was significantly more frequent in NO-FGR placentas. Maternal pre-eclampsia was more frequent in the FGR group than in the other group, but the difference was not statistically significant. We did not observe any difference between the groups regarding incidence and severity of RDS, incidence of PPHN, PDA pharmacological treatment and ligation. Duration of $\mathrm{O}_{2}$-therapy was significantly longer in the FGR infants compared with the NO-FGR infants. There were no differences between the two groups in terms of survival. Only one death after 36 weeks PMA occurred in the FGR group. Among the survived babies at 36 weeks of PMA, 12 out of $36(33 \%)$ of the FGR group developed BPD versus 8 out of $118(7 \%)$ of the NO-FGR group and the difference was statistically significant. We did not observe any case of periventricular leukomalacia in the study population. The incidence of severe forms of IVH (grade 3-4) was significantly higher in the NO-FGR group compared with the FGR group. The cause of delivery significantly differed between the groups: 'indicated preterm delivery' was more represented in the FGR group whereas 'spontaneous preterm delivery' was more common in the NO-FGR group. In 32 cases, the delivery was neither indicated nor spontaneous.

In order to understand the role of FGR in developing BPD, we made a univariable analysis between BPD and NO-BPD infants considering prenatal and neonatal factors. Of the 178 studied newborns, we analysed only the 154 babies survived until 36 weeks PMA(table 2). Significant risk factors for BPD were: BW, Apgar score at $5 \mathrm{~min}$, length of ventilation, severity of acute respiratory failure at birth, PPHN, pneumonia and sepsis. GA was lower in BPD infants, but this difference was not statistically significant. Neither histological chorioamnionitis nor maternal pre-eclampsia was associated with an increased BPD risk. Moreover, the 'indicated' preterm delivery was related 
Table 1 Prenatal and neonatal characteristics of the studied neonates

\begin{tabular}{llcc}
\hline & $\begin{array}{l}\text { FGR } \\
(\mathbf{n = 3 9 )}\end{array}$ & $\begin{array}{l}\text { NO-FGR } \\
(\mathbf{n = 1 3 9 )}\end{array}$ & p Value \\
\hline Gestational age (weeks) & $27.5 \pm 1.1$ & $26.7 \pm 1.7$ & $\mathbf{0 . 0 0 8}$ \\
\hline Birth weight (g) & $720 \pm 198$ & $927 \pm 242$ & $<.001$ \\
\hline Caesarean section & $37(95)$ & $110(79)$ & $\mathbf{0 . 0 3}$ \\
\hline Indicated preterm birth & $35(90)$ & $30(22)$ & $<\mathbf{0 . 0 0 1}$ \\
\hline Spontaneous preterm birth & $1(3)$ & $80(58)$ & $<\mathbf{0 . 0 0 1}$ \\
\hline Male sex & $19(49)$ & $72(52)$ & 0.73 \\
\hline Apgar score at 5 min & $7.8 \pm 1$ & $7.4 \pm 1.5$ & 0.14 \\
\hline Antenatal corticosteroids & $38(97)$ & $115(83)$ & $\mathbf{0 . 0 2}$ \\
\hline Histological chorioamnionitis & $2(5)$ & $34(31)$ & $\mathbf{0 . 0 0 6}$ \\
\hline Pre-eclampsia & $6(15)$ & $9(6)$ & 0.08 \\
\hline Birth weight z-score & $-1.22 \pm 0.8$ & $0.31 \pm 1.04$ & $<\mathbf{0 . 0 0 1}$ \\
\hline Small for gestational age & $15(38)$ & $9(6)$ & $<\mathbf{0 . 0 0 1}$ \\
\hline Respiratory distress syndrome & $32(82)$ & $101(75)$ & 0.23 \\
\hline Need of 2 or more doses of surfactant & $10(26)$ & $36(26)$ & 0.97 \\
\hline Persistent pulmonary hypertension of the newborn & $5(12)$ & $13(9)$ & 0.53 \\
\hline Length of ventilation (hours) & $305 \pm 393$ & $226 \pm 347$ & 0.22 \\
\hline Length of O - -therapy (hours) $_{\text {Pneumonia }}$ & $907 \pm 989$ & $556 \pm 837$ & $\mathbf{0 . 0 2}$ \\
\hline Sepsis & $17(44)$ & $41(29)$ & 0.10 \\
\hline Patent ductus arteriosus-pharmacological treatment & $14(36)$ & $51(37)$ & 0.93 \\
\hline Patent ductus arteriosus-surgical closure & $12(31)$ & $65(47)$ & 0.09 \\
\hline Survival & $4(10)$ & $18(13)$ & 0.65 \\
\hline Bronchopulmonary dysplasia* & $35(90)$ & $118(85)$ & 0.44 \\
\hline Severe intraventricular haemorrhage & $12(33)$ & $8(7)$ & $<\mathbf{0 . 0 0 1}$ \\
\hline Dat exps & $21(15)$ & $\mathbf{0 . 0 3}$ \\
\hline
\end{tabular}

Data expressed as mean \pm SD or $n(\%)$.

${ }^{*}$ Data are referred to the survived babies at 36 weeks postmenstrual age. FGR, fetal growth restriction.

to an increased BPD rate, whereas the 'spontaneous' delivery did not show any further BPD risk.

SGA infants were at higher risk for BPD and this risk increased in FGR-SGA infants: BPD developed in $1 / 7$ (14\%) of SGA-NO-FGR infants compared with 11/12 $(92 \%)$ of SGA-FGR infants (table 3). Accordingly, the severe forms of BPD were more represented in the SGA-FGR group.

We examined a logistic model in order to define the role of FGR in developing BPD, regardless of being SGA and other potential confounder factors. Table 4 presents the adjusted ORs and 95\% CI of the independent variables included in the final multivariable model. FGR was significantly associated with BPD risk (OR 5.1, CI 1.4 to 18.8, $\mathrm{p}=0.01$ ), independently from $\mathrm{BW} \mathrm{z}$-score that still remains a strong risk factor (OR 0.5 , CI 0.3 to $0.9, \mathrm{p}=0.01$ ).

\section{DISCUSSION}

Nowadays BPD is considered as a multifactorial disease resulting from arrest of lung development and other processes injuring the lungs before and on birth. ${ }^{21}{ }^{22}$ FGR has been indicated as a risk factor for BPD in newborns with an extremely low GA. ${ }^{34}$ Our data confirm that SGA infants are at high risk of developing BPD, regardless of GA and other factors involved in BPD development such as severity of RDS at birth, PPHN, mechanical ventilation and postnatal infectious insults. Moreover, the same data show that SGA infants are more likely to develop BPD when placenta dysfunction is the external cause of low BW. This confirms our hypothesis according to which in a cohort of preterm infants, the presence of uteroplacental insufficiency, based on fetal Doppler velocimetry abnormalities, is more associated with BPD risk than low BW per se. We may assume that placental insufficiency triggers a process affecting epigenetic fetal programme and this could explain both low BW and the worst respiratory outcome. This speculation is in agreement with the most recent literature showing that the concomitance of low BW and an adverse fetal environment leads to a high BPD risk. Recently, two large prospective population-based cohort studies have investigated this 
Table 2 Univariate analyses between BPD and NO-BPD infants

\begin{tabular}{|c|c|c|c|c|c|}
\hline & $\begin{array}{l}\text { BPD } \\
(n=20) \\
13 \%\end{array}$ & $\begin{array}{l}\text { NO-BPD } \\
(n=134) \\
87 \%\end{array}$ & OR & $\mathbf{C l}$ & p Value \\
\hline Gestational age (weeks) & $26.6 \pm 1.9$ & $27.2 \pm 1.4$ & 0.76 & 0.56 to 1.03 & 0.08 \\
\hline Birth weight (100 g) & $662 \pm 306$ & $946 \pm 209$ & 0.54 & 0.41 to 0.71 & $<0.0001$ \\
\hline Caesarean section & $17(85)$ & $117(87)$ & 0.82 & 0.22 to 3.11 & 0.77 \\
\hline Indicated preterm birth & $13(65)$ & $45(34)$ & 3.67 & 1.37 to 9.85 & 0.01 \\
\hline Spontaneous preterm birth & $5(25)$ & $61(45)$ & 0.40 & 0.14 to 1.16 & 0.09 \\
\hline Male sex & $13(65)$ & $65(48)$ & 1.97 & 0.74 to 5.24 & 0.17 \\
\hline Fetal growth restriction & $12(60)$ & $24(18)$ & 6.87 & 2.53 to 18.64 & $<0.0001$ \\
\hline Small for gestational age & $12(60)$ & $7(5)$ & 27.21 & 8.41 to 88.07 & $<0.0001$ \\
\hline Antenatal corticosteroids & $18(90)$ & $120(90)$ & 1.05 & 0.22 to 5.01 & 0.95 \\
\hline Birth weight $z$-score, 1 unit & $-1.08 \pm 1.56$ & $0.12 \pm 1.01$ & 0.38 & 0.23 to 0.62 & $<0.0001$ \\
\hline Histological chorioamnionitis & $2(10)$ & $27(20)$ & 0.40 & 0.08 to 1.91 & 0.25 \\
\hline Pre-eclampsia & $1(5)$ & $12(9)$ & 0.54 & 0.06 to 4.35 & 0.56 \\
\hline Apgar score at $5 \mathrm{~min}$ & $6.9 \pm 1.2$ & $7.8 \pm 1.2$ & 0.63 & 0.45 to 0.88 & 0.007 \\
\hline Respiratory distress syndrome & $15(75)$ & $94(70)$ & 1.27 & 0.43 to 3.75 & 0.66 \\
\hline Need of two or more doses of surfactant & $9(45)$ & $25(19)$ & 3.56 & 1.33 to 9.53 & 0.01 \\
\hline PPHN & $6(30)$ & $7(5)$ & 7.77 & 2.29 to 26.39 & 0.001 \\
\hline Ventilation length ( 24 hours) & $801 \pm 678$ & $155 \pm 198$ & 1.1 & 1.06 to 1.15 & $<0.0001$ \\
\hline Pneumonia & $15(75)$ & $31(23)$ & 9.97 & 3.35 to 29.61 & $<0.0001$ \\
\hline $\begin{array}{l}\text { Patent ductus arteriosus pharmacological } \\
\text { treatment }\end{array}$ & $10(50)$ & $55(41)$ & 1.43 & 0.56 to 3.68 & 0.45 \\
\hline Patent ductus arteriosus surgical closure & $6(30)$ & $14(10)$ & 0.40 & 0.08 to 1.91 & 0.25 \\
\hline Sepsis & $12(60)$ & $42(31)$ & 3.29 & 1.25 to 8.63 & 0.02 \\
\hline
\end{tabular}

Data expressed as mean \pm SD or $\mathrm{n}(\%)$.

BPD, bronchopulmonary dysplasia.

\begin{tabular}{lccc}
\hline Table 3 & BPD incidence according to birth weight and FGR \\
\hline & $\begin{array}{l}\text { Survived at } \\
\mathbf{3 6} \text { weeks }\end{array}$ & BPD* $^{*}$ & Severe BPD† \\
\hline $\begin{array}{l}\text { AGA-NO-FGR } \\
\text { n. } 130\end{array}$ & 111 & $7(6)$ & $5(4)$ \\
$\begin{array}{l}\text { AGA-FGR } \\
\text { n. } 24\end{array}$ & 24 & $1(4)$ & $1(4)$ \\
$\begin{array}{l}\text { SGA-NO-FGR } \\
\text { n. } 9\end{array}$ & 7 & $1(14)$ & $1(14)$ \\
$\begin{array}{l}\text { SGA-FGR } \\
\text { n. } 15\end{array}$ & 12 & $11(92)$ & $4(33)$ \\
\hline
\end{tabular}

Data expressed as $\mathrm{n}(\%)$.

${ }^{*} \mathrm{Need}$ of $\mathrm{O}_{2}$-therapy with or without positive-pressure ventilation at 36 weeks of postmenstrual age; data are referred to the survived babies at 36 weeks of postmenstrual age.

$\dagger$ Need of $\mathrm{O}_{2}$-therapy $\geq 30 \%$ and/or positive-pressure ventilation at 36 weeks of postmenstrual age; data are referred to the survived babies at 36 weeks of postmenstrual age.

AGA, appropriate for gestational age; BPD, bronchopulmonary dysplasia; FGR, fetal growth restriction; NO-BPD, babies without bronchopulmonary dysplasia; NO-FGR, babies without fetal growth restriction; SGA, small for gestational age. issue: one showed that the risk of moderate to severe BPD is high in pregnancies with fetal disorders but not in those with maternal disorders only ${ }^{8}$ and the other one showed an increased risk of death and BPD associated with disorder of placentation as compared with presumed infection/inflammation, especially when vascular disorders were associated with a low BW. ${ }^{9}$ Accordingly, in our study, we observed an increased rate of BPD among babies born from a vascular disorder-associated preterm delivery, but mostly we found a significantly higher BPD risk among FGR-SGA infants. Placental insufficiency leads to chronic fetal hypoxia; fetuses adapt to chronic hypoxia via redistribution of

Table 4 Risk factors for bronchopulmonary dysplasia: multivariable analysis

\begin{tabular}{llll}
\hline Variable* $^{*}$ & OR & $\mathbf{9 5 \%} \mathbf{C l}$ & p Value \\
\hline Fetal growth restriction & 5.10 & 1.39 to 18.8 & $\mathbf{0 . 0 1}$ \\
Birth weight z-score & 0.50 & 0.28 to 0.88 & $\mathbf{0 . 0 1}$ \\
Apgar score at 5 min & 0.52 & 0.34 to 0.80 & $\mathbf{0 . 0 0 3}$ \\
\hline
\end{tabular}

${ }^{\star}$ Final model after likelihood ratio test. 
cardiac output. Reduced perfusion of splanchnic organs during development causes relative hypoxia/ischaemia that can lead to various disorders in postnatal life. ${ }^{10}$ Placenta acts as the director of the whole fetal development and its pathology has already been associated with lung and vascular disease in the offspring: Mestan et al have shown that maternal placental vascular underperfusion is associated with the development of BPD among preterm infants. ${ }^{11}$ Fetal Doppler examination enables clinicians to identify placental underperfusion and the resulting adverse fetal environment. Experimental sheep FGR models have highlighted impaired lung function and structure as well as endothelial dysfunction in growth-restricted offspring suggesting that placental insufficiency may impair both pulmonary angiogenesis and alveolarisation. ${ }^{23}{ }^{24} \mathrm{~A}$ recent experimental study has shown that intrauterine growth-restricted lambs did not differ from control lambs in terms of lung function, structure, inflammation and response to ventilation after 1 week of placental dysfunction. ${ }^{25}$ The authors did not examine the endothelial function and its role in the respiratory outcomes. Moreover, placental insufficiency was either too short in duration or too late in gestation to induce structural changes in the lung. It is possible that the time of onset and the duration of placental insufficiency are essential in lung development. Interestingly, in our cohort population, FGR AGA infants did not show any further BPD risk compared with NO-FGR AGA infants, probably because their exposure to an abnormal intrauterine environment was not long enough to cause neither low BW nor lung susceptibility.

Soudée et al showed that antenatal growth-restricted infants are at higher risk of BPD, regardless of their GA at birth. ${ }^{26}$ Interestingly, in our population BPD and NO-BPD infants have similar GA, confirming that placental insufficiency could influence lung development more than immaturity alone.

The association between BPD and pre-eclampsia is controversial. ${ }^{27-29}$ Our data do not show any association between BPD and pre-eclampsia when considered independently from FGR.

The role of antenatal inflammation in developing BPD remains unclear. ${ }^{30}$ In our cohort, BPD risk does not seem to be increased by histological chorioamnionitis or by an inflammatory condition triggering delivery regardless of placenta histology.

The Apgar score at $5 \mathrm{~min}$ was strongly related to BPD risk, as already suggested by previous observational studies. ${ }^{31} 32$ A higher need of resuscitation at birth could be the consequence of an adverse fetal environment that could affect lung development; moreover, lung injuries caused by invasive ventilation in the delivery room are a well-known occurrence. ${ }^{33}$

As previously reported, ${ }^{34}$ FGR infants did not differ from the others in terms of RDS. Nevertheless, the significantly higher exposure of our FGR infants to antenatal steroids may have played a protective role against RDS development.
We found a lower IVH rate in the FGR group probably because they had a higher GA and they received prenatal steroids more often than the other newborns, although the influence of FGR on brain injury is still unclear. ${ }^{35} 36$

Our study has some limitations. The small sample size of BPD infants could limit the power to detect differences between groups and might have affected the accuracy of our estimates. Moreover, the statistical power of the study does not allow us to reach some conclusions on several non-significant associations that we observe in our cohort (such as BPD and histological chorioamnionitis or FGR and RDS). Doppler differences in relation to the small sample of the study group are not considered as well as how long exactly was the fetus exposed to abnormal Doppler flows.

In conclusion, SGA preterm infants show the highest BPD risk when placenta dysfunction is the external cause of low BW. We suggest umbilical artery Doppler velocimetry as a tool for identifying high-BPD risk preterm infants, as we strongly believe that characterising fetal environment will be mandatory in future neonatal medicine. Nevertheless, clinicians should be aware that this tool carries with it a risk of false positive results. Further research is needed to investigate thoroughly the link between placenta dysfunction and lung disease.

Contributors All the authorsincluded on the paper fulfil the criteria of authorship as stated by the ICMJERecommendations. Each author listed on the manuscript has seen and approved thesubmission of this version of the manuscript and takes full responsibility for themanuscript. There is not anyone else who fulfils the criteria that has beenexcluded as an author. AL gave substantial contributions to the conception anddesign of the work and to the interpretation of data. She wrote the first draftof the work and approved the final revisited version of it. PR gave substantialcontributions to the conception and design of the work and to theinterpretation of data. He revisited the work critically and approved the finalrevisited version of it. RP gave substantial contributions to the design of thework; she was responsible for the analysis of data and collaborated to theirinterpretation. She revisited the work critically and approved the finalsubmitted version of it. FC gave substantial contributions to the design of thework, to the analysis and interpretation of data; he revisited it criticallyand approved the final version to be published. MT CT, CA, CR and AP wereresponsible for the acquisition of neonatal data; they revisited the workcritically and approved final version to be published. AG was responsible forthe acquisition of neonatal data; he revisited the work critically and approvedfinal version to be published. IM gave substantial contributions to the designof the work and was responsible for the acquisition of prenatal data; sherevisited the work critically and approved final version to be published. SBwas responsible for the acquisition of prenatal data; she revisited the workcritically and approved final version to be published. GFZ gave substantialcontributions to the design of the work and to the acquisition of data aboutplacental histopathology. He revisited the work critically and approved thefinal revisited version of it. CR gave substantial contributions to the designof the work. He revisited the work critically and approved the final revisitedversion of it. GV gave substantial contributions to the conception and designof the work and to the interpretation of data. He revisited the work criticallyand approved the final revisited version of it. All authors agree to beaccountable for all aspects of the work in ensuring that questions related tothe accuracy or integrity of any part of the work are appropriatelyinvestigated and resolved.

Funding This research received no specific grant from any funding agency in the public, commercial or not-for-profit sector.

Competing interests There is no potential conflict of interest, real or perceived in: (1) study design; (2) the collection,analysis and interpretation of data; (3) the writing of the report and (4) the decision to submit the paper for publication.

Ethics approval Universita' Cattolica del Sacro Cuore Ethics Committee.

Provenance and peer review Not commissioned; externally peer reviewed. 
Data sharing statement № additional data available.

Open Access This is an Open Access article distributed in accordance with the Creative Commons Attribution Non Commercial (CC BY-NC 4.0) license, which permits others to distribute, remix, adapt, build upon this work non-commercially, and license their derivative works on different terms, provided the original work is properly cited and the use is non-commercial. See: http://creativecommons.org/ licenses/by-nc/4.0/

(C) Article author(s) (or their employer(s) unless otherwise stated in the text of the article) 2017. All rights reserved. No commercial use is permitted unless otherwise expressly granted.

\section{REFERENCES}

1. Jobe AH. The new bronchopulmonary dysplasia. Curr Opin Pediatr 2011;23:167-72

2. Anderson PJ, Doyle LW. Neurodevelopmental outcome of bronchopulmonary dysplasia. Semin Perinatol 2006;30:227-32.

3. Bose C, Van Marter LJ, Laughon M, et al. Fetal growth restriction and chronic lung disease among infants born before the 28th week of gestation. Pediatrics 2009;124:e450-8.

4. Zeitlin J, El Ayoubi M, Jarreau PH, et al. Impact of fetal growth restriction on mortality and morbidity in a very preterm birth cohort. $J$ Pediatr 2010;157:733-9.

5. Durrmeyer X, Kayem G, Sinico M, et al. Perinatal risk factors for bronchopulmonary dysplasia in extremely low gestational age infants: a pregnancy disorder-based approach. J Pediatr 2012;160:578-83.

6. Pike K, Jane Pillow J, Lucas JS. Long term respiratory consequences of intrauterine growth restriction. Semin Fetal Neonatal Med 2012;17:92-8.

7. Figueras F, Gardosi J. Intrauterine growth restriction: new concepts in antenatal surveillance, diagnosis, and management. Am J Obstet Gynecol 2011;204:288-300.

8. Torchin H, Ancel PY, Goffinet F, et al. Placental complications and bronchopulmonary dysplasia: epipage-2 Cohort Study. Pediatrics 2016;137:e20152163.

9. Gagliardi L, Rusconi F, Da Frè M, et al. Pregnancy disorders leading to very preterm birth influence neonatal outcomes: results of the population-based ACTION cohort study. Pediatr Res 2013;73:794-801.

10. Gagnon R. Placental insufficiency and its consequences. Eur J Obstet Gynecol Reprod Biol 2003;110(suppl 1):S99-S107.

11. Mestan KK, Check J, Minturn L, et al. Placental pathologic changes of maternal vascular underperfusion in bronchopulmonary dysplasia and pulmonary hypertension. Placenta 2014;35:570-4.

12. Bertino E, Spada E, Occhi L, et al. Neonatal anthropometric charts: the italian neonatal study compared with other european studies. $J$ Pediatr Gastroenterol Nutr 2010;51:353-61.

13. Diagnosis and management of Preeclampsia and Eclampsia ACOG Practice Bulletin. 2002;33:1.

14. Redline RW, Faye-Petersen O, Heller D, et al. Amniotic infection syndrome: nosology and reproducibility of placental reaction patterns. Pediatr Dev Pathol 2003;6:435-48.

15. McElrath TF, Hecht JL, Dammann O, et al. Pregnancy disorders that lead to delivery before the 28th week of gestation: an epidemiologic approach to classification. Am J Epidemiol 2008;168:980-9.

16. Shennan AT, Dunn MS, Ohlsson A, et al. Abnormal pulmonary outcomes in premature infants: prediction from oxygen requirement in the neonatal period. Pediatrics 1988;82:527-32.
17. Perlman JM, Wyllie J, Kattwinkel J, et al. Neonatal resuscitation: 2010 International Consensus on Cardiopulmonary Resuscitation and Emergency Cardiovascular Care Science with treatment recommendations. Pediatrics 2010;126:e1319-44.

18. Vento G, Matassa PG, Ameglio F, et al. HFOV in premature neonates: effects on pulmonary mechanics and epithelial lining fluid cytokines. A randomized controlled trial. Intensive Care Med 2005;31:463-70.

19. Su BH, Watanabe T, Shimizu M, et al. Echocardiographic assessment of patent ductus arteriosus shunt flow pattern in premature infants. Arch Dis Child Fetal Neonatal Ed 1997;77:F36-F40.

20. Lewis F, Butler A, Gilbert L. A unified approach to model selection using the likelihood ratio test. Methods Ecol Evol 2011;2(2):155-62.

21. Coalson JJ. Pathology of new bronchopulmonary dysplasia. Semin Neonatol 2003;8:73-81.

22. Charafeddine L, D'Angio CT, Phelps DL. Atypical chronic lung disease patterns in neonates. Pediatrics 1999;103:759-65.

23. Joyce BJ, Louey S, Davey MG, et al. Compromised respiratory function in postnatal lambs after placental insufficiency and intrauterine growth restriction. Pediatr Res 2001;50:641-9.

24. Rozance PJ, Seedorf GJ, Brown A, et al. Intrauterine growth restriction decreases pulmonary alveolar and vessel growth and causes pulmonary artery endothelial cell dysfunction in vitro in feta sheep. Am J Physiol Lung Cell Mol Physiol 2011;301:860-71.

25. Allison BJ, Hooper SB, Coia E, et al. Ventilation-induced lung injury is not exacerbated by growth restriction in preterm lambs. Am J Physiol Lung Cell Mol Physiol 2016;310:L213-L223.

26. Soudée S, Vuillemin L, Alberti C, et al. Fetal growth restriction is worse than extreme prematurity for the developing lung. Neonatology 2014;106:304-10.

27. Hansen AR, Barnés CM, Folkman J, et al. Maternal preeclampsia predicts the development of bronchopulmonary dysplasia. J Pediatr 2010;156:532-6.

28. O'Shea JE, Davis PG, Doyle LW; Victorian Infant Collaborative Study Group. Maternal preeclampsia and risk of bronchopulmonary dysplasia in preterm infants. Pediatr Res 2012;71:210-4.

29. Yen TA, Yang HI, Hsieh WS, et al. Preeclampsia and the risk of bronchopulmonary dysplasia in VLBW infants: a population based study. PLoS One 2013;8:e75168.

30. Hartling L, Liang Y, Lacaze-Masmonteil T. Chorioamnionitis as a risk factor for bronchopulmonary dysplasia: a systematic review and meta-analysis. Arch Dis Child Fetal Neonatal Ed 2012;97:F8-F17.

31. Eriksson L, Haglund B, Odlind V, et al. Perinatal conditions related to growth restriction and inflammation are associated with an increased risk of bronchopulmonary dysplasia. Acta Paediatr 2015;104:259-63.

32. Lapcharoensap W, Gage SC, Kan P, et al. Hospital variation and risk factors for bronchopulmonary dysplasia in a population-based cohort. JAMA Pediatr 2015;169:e143676.

33. Hillman NH, Moss TJ, Kallapur SG, et al. Brief, large tidal volume ventilation initiates lung injury and a systemic response in fetal sheep. Am J Respir Crit Care Med 2007;176:575-81.

34. De Jesus LC, Pappas A, Shankaran S, et al. Outcomes of smal for gestational age infants born at $<27$ weeks' gestation. J Pediatr 2013;163:55-60.

35. Keunen K, Kersbergen KJ, Groenendaal F, Kj K, et al. Brain tissue volumes in preterm infants: prematurity, perinatal risk factors and neurodevelopmental outcome: a systematic review. J Matern Fetal Neonatal Med 2012;25 Suppl 1:89-100.

36. Malhotra A, Yahya Z, Sasi A, et al. Does fetal growth restriction lead to increased brain injury as detected by neonatal cranial ultrasound in premature infants? J Paediatr Child Health 2015;51:1103-8. 